\title{
Enhanced Nitrogen Fixation and Competitiveness for Nodulation of Lotus pedunculatus by a Plasmid-cured Derivative of Rhizobium loti
}

\author{
By CLIVE E. PANKHURST,* PAULINE E. MACDONALD AND \\ JANICE M. REEVES \\ Applied Biochemistry Division, Department of Scientific and Industrial Research, \\ Palmerston North, New Zealand
}

(Received 18 December 1985; revised 2 March 1986)

\begin{abstract}
A plasmid-cured derivative of Rhizobium loti strain NZP2037, strain PN4010, was significantly more effective in $\mathrm{N}_{2}$ fixation and showed an improved capacity to compete with other root nodule bacteria for nodulation of Lotus pedunculatus, relative to that of strain NZP2037. Reintroduction of the plasmid pRlo2037 into PN4010 resulted in a return to the NZP2037 level of symbiotic effectiveness and competitiveness. The enhanced effectiveness and competitiveness of PN4010 for L. pedunculatus was associated with its increased capacity to form nodules. Strain PN4010 did not differ from NZP2037 in its growth characteristics in pure culture, in its resistance to $L$. pedunculatus root flavolan or in its ability to multiply in the $L$. pedunculatus rhizosphere in the presence of a competing strain of $R$. loti. An examination of $35 R$. loti strains (including 25 field isolates) revealed two strains (NZP2014 and NZP2042) that did not contain a single large indigenous plasmid; both were significantly more effective in $\mathrm{N}_{2}$ fixation with $L$. pedunculatus than was NZP2037 or two other $\mathrm{Nod}^{+} \mathrm{Fix}^{+}$plasmid-containing strains of $R$. loti. Transfer of pRlo2037 into NZP2014 and NZP2042 reduced their effectiveness for $L$. pedunculatus.
\end{abstract}

\section{INTRODUCTION}

In Rhizobium meliloti and $R$. leguminosarum (which now includes the former species $R$. phaseoli and $R$. trifolii; Jordan, 1984), genes involved in root nodule development and $\mathrm{N}_{2}$ fixation with legumes are located on large indigenous plasmids (reviewed by Dénarié et al., 1981 and Kondorosi et al., 1984). In contrast, these genes appear to be chromosomally located in the limited number of strains of Bradyrhizobium sp. that have been examined (Haugland \& Verma, 1981; Masterson et al., 1982). This difference in the location of nodulation (nod) and nitrogen fixation (nif) genes may reflect an evolutionary divergence between the two types of root-nodule bacteria (Pankhurst, 1986).

Rhizobium loti (Jarvis et al., 1982) nodulates the agriculturally important pasture legume Lotus as well as a number of other legumes (Pankhurst, 1977; Jarvis et al., 1982). A single large plasmid has been found in each of the two strains of $R$. loti (strains NZP2037 and NZP2213) so far examined (Pankhurst et al., 1983). However, unlike the plasmids present in other Rhizobium species, those in strains NZP2037 and NZP2213 (pRlo2037 and pRlo2213 respectively) do not carry symbiotic genes (Pankhurst et al., 1983; Chua et al., 1985). Plasmid-cured derivatives of NZP2037 and NZP2213 still formed effective ( $\mathrm{N}_{2}$-fixing) root nodules on Lotus species (Chua et al., 1985).

While testing $R$. loti strain NZP2037 and its plasmid-cured derivative strain PN4010 for symbiotic effectiveness on Lotus pedunculatus and Lotus tenuis, it was noted that PN4010 fixed noticeably more $\mathrm{N}_{2}$ with $L$. pedunculatus than did NZP2037. We have sought to confirm this observation and to see if PN4010 acquired any other attributes, e.g. an improved capacity to compete with other $R$. lot $i$ strains for nodulation of $L$. pedunculatus, as a consequence of losing 
plasmid pRlo2037. In addition we have screened a collection of wild-type $R$. lot $i$ strains for the presence of plasmids, with the aim of determining whether naturally occurring 'plasmid-minus' strains of $R$. loti exist. The symbiotic effectiveness of two such 'plasmid-minus' strains on $L$. pedunculatus and $L$. tenuis was evaluated.

\section{METHODS}

Bacterial strains and plasmids. These are listed in Table 1.

In a previous study, $R$. loti strain NZP2037 was cured of its 240 MDa plasmid (pRlo2037) by heat treatment of

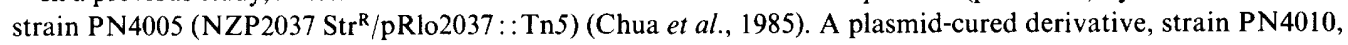
was subsequently obtained. In addition, a cointegrate between pRlo2037:: Tn 5 and pJB3JI was constructed (plasmid pPN360) and maintained in Escherichia coli strain PN440 (Chua et al., 1985). The cointegrate plasmid pPN360 was transferred back into PN4010 to produce strain PN4012. Field isolates of $R$. lot $i$ were made from the nodules of L. tenuis plants collected from three different localities near Palmerston North, New Zealand. Each isolate was single-colony-purified and tested for its ability to form $\mathrm{Nod}^{+} \mathrm{Fix}^{+}$nodules on L. tenuis before it was used in the experiments.

Bacterial manipulations. Rhizobium and Bradyrhizobium cultures were grown at $28^{\circ} \mathrm{C}$ in either $\mathrm{M}^{+}$medium (Pankhurst, 1977), or S20 medium (Chua et al., 1985) supplemented as required with neomycin (Neo; $400 \mu \mathrm{g} \mathrm{ml}^{-1}$ ), rifampicin (Rif; $100 \mu \mathrm{g} \mathrm{ml}^{-1}$ ), streptomycin (Str; $250 \mu \mathrm{g} \mathrm{ml}^{-1}$ ) or tetracycline $\left(\mathrm{Tc} ; 2 \mu \mathrm{g} \mathrm{m}^{-1}\right) . E$. coli cultures were grown in LB medium (Miller, 1972), with tetracycline $\left(15 \mu \mathrm{g} \mathrm{ml}^{-1}\right)$ and kanamycin $(\mathrm{Km}$; $30 \mu \mathrm{g} \mathrm{mi}^{-1}$ ) when necessary. Bacterial crosses were done as patch matings (Banfalvi et al., 1981). Tests for flavolan resistance of rhizobia were as described by Pankhurst \& Jones (1979).

Analysis of plasmids. Plasmids were detected in Rhizobium strains using a modification of the agarose gel method (Eckhardt, 1978) as described by Scott \& Ronson (1982).

Symbiotic effectiveness. Three Lotus species, L. pedunculatus Cav. 'Grasslands Maku', L. angustissimus L. and $L$. tenuis Waldst. et $\mathrm{K}$ it. were used to evaluate the symbiotic effectiveness (nodulation and $\mathrm{N}_{2}$ fixation) of different $R$.

Table 1. Bacterial strains and plasmids

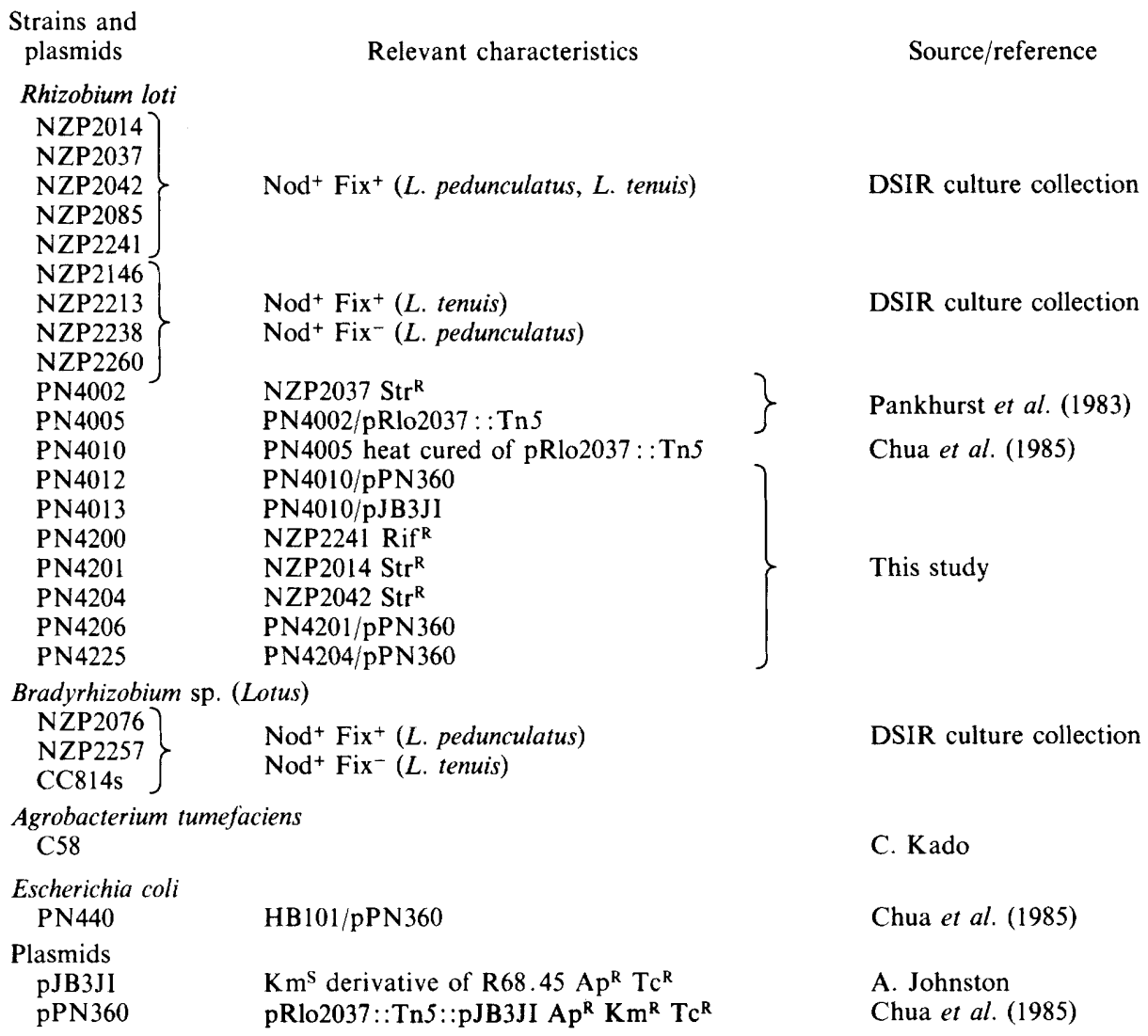


loti strains. The plants were grown under bacteriologically controlled conditions in jars of sterile pumice (Pankhurst \& Jones, 1979) in a growth cabinet with a $12 \mathrm{~h}$ photoperiod (light intensity $180 \mathrm{~W} \mathrm{~m}^{2}$ ) with temperatures of $24^{\circ} \mathrm{C}$ day, $20^{\circ} \mathrm{C}$ night. At various times after inoculation with the test Rhizobium, plants from three to five replicate jars were removed and the roots washed free of pumice. The nodulated roots of individual plants were then blotted dry and their nitrogenase activity determined by acetylene reduction (Pankhurst \& Jones, 1979). The nodules, roots and shoots of each plant were then dried overnight at $100^{\circ} \mathrm{C}$ and weighed.

Rhizobium competition experiments. L. pedunculatus seedlings were grown on slopes of nitrogen-free agar medium in $15 \times 1.5 \mathrm{~cm}$ test tubes (Pankhurst, 1981). Seedlings were inoculated with bacteria $3 \mathrm{~d}$ after they were sown in the tubes and the tubes were then placed in a growth cabinet. Bacterial cultures used for plant inoculation were grown on $\mathrm{M}^{+}$agar for 2 to $4 \mathrm{~d}$ at $28^{\circ} \mathrm{C}$. The bacteria were scooped into $10 \mathrm{ml}$ sterile water and the resultant suspensions adjusted to an $\mathrm{OD}_{600}$ of 0.1 (about $1 \times 10^{8}$ bacteria $\mathrm{ml}^{-1}$ ) by the addition of extra water where necessary. Cultures were then mixed in equal proportion and $1 \mathrm{ml}$ of each mixture was added to 12 L. pedunculatus seedlings. Seedlings inoculated with each test culture on its own were included as controls in each experiment. The number of viable bacteria in the inoculum was determined by plate counts made at the time of plant inoculation. The number of bacteria in the tubes at various times after inoculation was estimated as described by Pankhurst (1981). To identify bacteria in nodules, the latter were excised from the plant roots, surface-sterilized with a $1: 1$ $(\mathrm{v} / \mathrm{v})$ solution of $95 \%(\mathrm{v} / \mathrm{v})$ ethanol and hydrogen peroxide for $1 \mathrm{~min}$, rinsed 6 times with sterile water, crushed and their contents streaked onto $\mathbf{M}^{+}$medium with or without addition of selective antibiotics. After incubation at $28{ }^{\circ} \mathrm{C}$ for 2 to $5 \mathrm{~d}$ the plates were examined for the presence or absence of bacterial growth.

\section{RESULTS}

\section{Plasmid content and symbiotic effectiveness of NZP2037}

To investigate the effect of pRlo2037 on the symbiotic effectiveness of NZP2037, strains PN4005, PN4010 and PN4012 were evaluated on L. pedunculatus, L. angustissimus and L tenuis (Table 2). L. angustissimus was included in this experiment as it is similar to L.pedunculatus in its response to different $R$. loti strains (Pankhurst \& Jones, 1979). Strain PN4010 was significantly more effective on L. pedunculatus and L. angustissimus than strains PN4005 or PN4012. After 6

\section{Table 2. Effect of R. loti strains PN4005, PN4010 and PN4012 on the growth, nodulation and} nitrogenase activity of three Lotus species

Plants were harvested and assayed 6 weeks after inoculation. The values for plant dry weight are means of 12 individual plants from four replicate jars (three plants per jar). All other values are means of nine individual plants from three replicate jars (three plants per jar). LSD, Least significant difference.

\begin{tabular}{|c|c|c|}
\hline $\begin{array}{l}\text { Lotus species } \\
\text { and } R . \text { lot } i \\
\text { strain }\end{array}$ & $\begin{array}{l}\text { Plant dry } \\
\text { wt (mg) }\end{array}$ & $\begin{array}{l}\text { No. of } \\
\text { nodules }\end{array}$ \\
\hline \multicolumn{3}{|l|}{ L. pedunculatus } \\
\hline PN4005 & $91 \cdot 1$ & $38 \cdot 8$ \\
\hline PN4010 & $147 \cdot 6$ & $64 \cdot 0$ \\
\hline PN4012 & $82 \cdot 2$ & $34 \cdot 4$ \\
\hline Uninoculated & $16 \cdot 5$ & 0 \\
\hline $\operatorname{LSD}(P=0.05)$ & $11 \cdot 6$ & $12 \cdot 3$ \\
\hline \multicolumn{3}{|l|}{ L. angustissimus } \\
\hline PN4005 & $85 \cdot 2$ & $55 \cdot 3$ \\
\hline PN4010 & $123 \cdot 6$ & $72 \cdot 1$ \\
\hline PN4012 & $67 \cdot 8$ & $51 \cdot 4$ \\
\hline Uninoculated & $14 \cdot 6$ & 0 \\
\hline $\operatorname{LSD}(P=0.05)$ & $12 \cdot 8$ & $16 \cdot 1$ \\
\hline \multicolumn{3}{|l|}{ L. tenuis } \\
\hline PN4005 & $182 \cdot 8$ & $20 \cdot 7$ \\
\hline PN4010 & $184 \cdot 5$ & $25 \cdot 2$ \\
\hline PN4012 & $171 \cdot 5$ & $19 \cdot 3$ \\
\hline Uninoculated & $31 \cdot 3$ & 0 \\
\hline $\operatorname{LSD}(P=0.05)$ & $10 \cdot 9$ & $11 \cdot 3$ \\
\hline
\end{tabular}

Nodule dry
wt per
plant (mg)

$13 \cdot 8$
$25 \cdot 4$
$12 \cdot 1$
0
$3 \cdot 7$

$22 \cdot 0$
$28 \cdot 2$
$17 \cdot 5$
0
$5 \cdot 1$

$13 \cdot 7$
$14 \cdot 9$
$12 \cdot 0$
0
$5 \cdot 9$

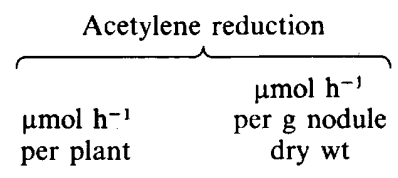

$\begin{array}{cc}1.06 & 76 \cdot 8 \\ 2 \cdot 12 & 83 \cdot 4 \\ 0 \cdot 82 & 67 \cdot 8 \\ 0 & 0 \\ 0.36 & 11.9 \\ & \\ 1.48 & 67 \cdot 3 \\ 2.29 & 81 \cdot 2 \\ 1 \cdot 11 & 63 \cdot 4 \\ 0 & 0 \\ 0.44 & 13 \cdot 3 \\ & \\ 1 \cdot 26 & 92 \cdot 0 \\ 1.42 & 95.4 \\ 0.91 & 75.8 \\ 0 & 0 \\ 0.42 & 10.6\end{array}$



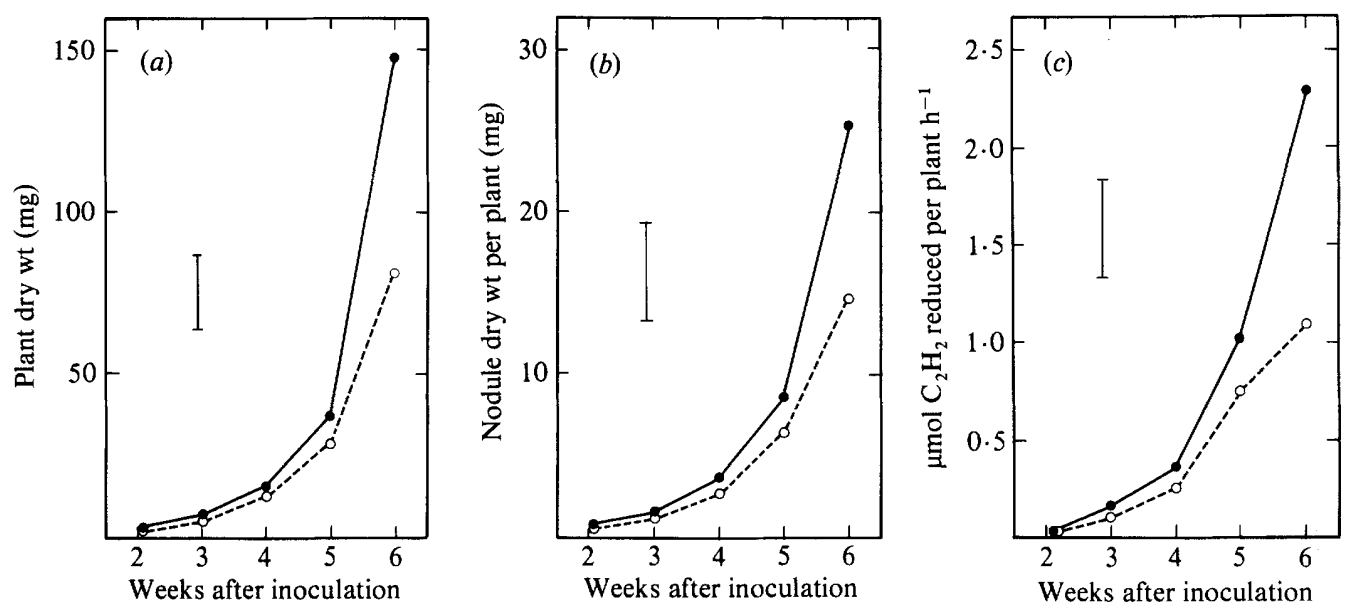

Fig. 1. Increases with time in plant dry weight $(a)$, nodule dry weight $(b)$ and acetylene reduction activity $(c)$ of $L$. pedunculatus plants inoculated with strain PN4010 (O) or strain PN4005 (O). The vertical bar in each figure indicates the LSD (least significant difference; $P=0.05$ ).

weeks growth $L$. pedunculatus and $L$. angustissimus plants inoculated with strain PN4010 had significantly more dry weight, nodules, nodule dry weight and nitrogenase activity per plant than plants inoculated with strain PN4005. However, the nitrogenase activity of the nodules formed by PN4010 and PN4005 on these two legumes was very similar (Table 2). Strain PN4012 exhibited a level of effectiveness comparable to that of PN4005 on both of these hosts. On $L$. tenuis there appeared to be no significant difference between the three strains in symbiotic effectiveness (Table 2). As controls to this experiment, no difference was observed between strains PN4005 and NZP2037 or between strains PN4010 and PN4013 (PN4010/pJB3JI) in symbiotic effectiveness on each of the three Lotus species.

Quantitative differences between strains PN4005 and PN4010 on L. pedunculatus (plant dry weight, nodule dry weight and plant nitrogenase activity) were measured over a 6 week growth period (Fig. 1). After 2 weeks, plants inoculated with strain PN4010 were more advanced in terms of total dry weight and nodule mass than plants inoculated with strain PN4005, and the differences became significant at 6 weeks. Both strains PN4005 and PN4010 caused root nodules to appear $10 \mathrm{~d}$ after inoculation.

\section{Plasmid content and nodulation competitiveness of NZP2037}

To test whether plasmid pRlo2037 could influence the nodulation competitiveness of strain NZP2037 the ability of strains PN4005, PN4010 and PN4012 to compete with other root nodule bacteria for nodulation of $L$. pedunculatus was examined. Each strain was tested against three other strains of $R$. loti and against three strains of Bradyrhizobium sp. (Lotus) (Table 3). The plasmid-cured strain PN4010 was a more efficient competitor than either of its plasmidcontaining counterparts. This was particularly evident when $R$. loti strains NZP2241 and NZP2085 and Bradyrhizobium sp. (Lotus) strains NZP2257 and CC814s were competitors (Table 3). In competition with $R$. loti strain NZP2014, strain PN4010 performed only slightly better than strain PN4005 or PN4012.

One possible explanation for the enhanced competitiveness of strain PN4010 relative to that of PN4005 was that PN4010 bacteria achieved greater proportional representation in the rhizosphere in competition with the other strains than did strain PN4005. To test this, $L$. pedunculatus seedlings were inoculated with a low concentration $\left(1 \times 10^{3}\right.$ bacteria $\left.\mathrm{ml}^{-1}\right)$ of PN4005 or PN4010 together with strain PN4200 (a rifampicin-resistant derivative of $R$. loti strain NZP2241). The number of PN4005, PN4010 and PN4200 rhizobia in the plant tubes was then followed over a 2 week period, until nodules were clearly visible. There was no apparent difference between strains PN4005 or PN4010 in their ability to grow in the presence of the competing strain PN4200 (data not shown). 


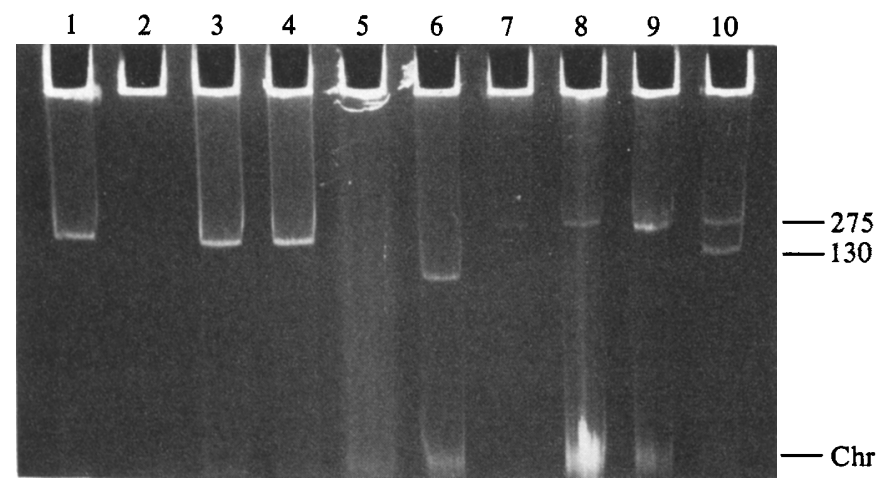

Fig. 2. Agarose gel electrophoresis of plasmids in $R$. loti and the reference strain $A$. tumefaciens C58. Lane $1, R$. loti NZP2037; lane 2, $R$. loti NZP2014; lane 3, $R$. loti NZP2085; lane 4, $R$. loti NZP2241; lane $5, R$. lot $i$ NZP2042; lane 6, $R$. loti NZP2213; lane 7, $R$. loti NZP2260; lane $8, R$. loti NZP2146; lane 9, $R$. loti NZP2238; lane 10, A. tumefaciens C58. Numbers indicate molecular size in MDa. Chr, chromosomal and linear DNA.

Table 3. Competition between R. loti strains PN4005, PN4010, PN4012 and other R. loti and Bradyrhizobium sp. (Lotus) strains for nodulation of L. pedunculatus

Five nodules from each of 126 -week-old plants (total of 60 nodules) were tested for the presence of PN4005, PN4010 and PN4012 (streptomycin resistant). A minority (1 to $5 \%$ ) of mixed nodules (containing both $\mathrm{Str}^{\mathrm{R}}$ and $\mathrm{Str}^{\mathrm{S}}$ bacteria) have not been included.

\begin{tabular}{lrcr}
\multicolumn{1}{c}{$\begin{array}{c}c \\
\text { Pompeting } \\
\text { strain }\end{array}$} & $\overbrace{\text { PN4005 }}^{\text {Pedules containing: }}$ \\
n. loti & & PN4010 & PN4012 \\
NZP2014 & 32.5 & 57.5 & 28.7 \\
NZP2085 & 43.7 & 81.2 & 33.7 \\
NZP2241 & 55.0 & 100.0 & 21.5 \\
Bradyrhizobium sp. (Lotus) & & & \\
NZP2076 & 25.0 & 41.8 & 18.7 \\
NZP2257 & 28.7 & 83.7 & 16.2 \\
CC814s & 0.0 & 31.2 & 0.0
\end{tabular}

Growth rate and resistance to flavolans

The effect of plasmid pRlo2037 on the growth rate and sensitivity of strain NZP2037 to the $L$. pedunculatus root flavolan (Pankhurst \& Jones, 1979) was examined. No difference in rates of growth of strains PN4005 and PN4010 in $\mathbf{M}^{+}$or S20 medium could be detected: during exponential growth both strains had a doubling time of $5.5 \mathrm{~h}$ in $\mathrm{M}^{+}$and $6.5 \mathrm{~h}$ in S20 medium. Similarly, no difference between the two strains in their sensitivity to the L. pedunculatus root flavolan was observed (data not shown).

\section{Plasmid content and symbiotic effectiveness of field and laboratory strains of $R$. lot $i$}

To determine if differences in symbiotic effectiveness amongst wild-type $R$. lot $i$ strains for Lotus species was correlated with their plasmid content, a collection of 25 field isolates and nine laboratory strains (including strain NZP2037) were examined for plasmids. Using the Eckhardt lysis procedure, all of the field isolates and seven of the laboratory strains were found to contain a single large plasmid with a molecular weight of 120 to $270 \mathrm{MDa}$. Only two of the laboratory strains, NZP2014 and NZP2042 (Fig. 2, lanes 2 and 5) did not appear to contain a plasmid. This was confirmed in several repeat experiments.

The nine laboratory strains were each evaluated for their symbiotic effectiveness with $L$. pedunculatus and L. ten:is (Table 4). All formed $\mathrm{N}_{2}$-fixing $\left(\mathrm{Nod}^{+}\right.$Fix ${ }^{+}$) nodules on L. tenuis and 
Table 4. Effect of $R$. loti strains on the dry weight of L. pedunculatus and L. tenuis plants

Plants were harvested 6 weeks after inoculation. The figures given are the mean dry weight of 12 individual plants grown in four replicate jars (three plants per jar). LSD, Least significant difference.

\begin{tabular}{|c|c|c|c|c|c|}
\hline \multirow[b]{2}{*}{$\begin{array}{l}\text { Rhizobium } \\
\text { strain }\end{array}$} & \multirow{2}{*}{$\begin{array}{l}\text { Presence } \\
\text { of an } \\
\text { indigenous } \\
\text { plasmid* }\end{array}$} & \multicolumn{2}{|c|}{ L. pedunculatus } & \multicolumn{2}{|c|}{ L. tenuis } \\
\hline & & $\begin{array}{l}\text { Symbiotic } \\
\text { phenotype }\end{array}$ & $\begin{array}{l}\text { Plant dry } \\
\text { wt (mg) }\end{array}$ & $\begin{array}{l}\text { Symbiotic } \\
\text { phenotype }\end{array}$ & $\begin{array}{c}\text { Plant dry } \\
\text { wt (mg) }\end{array}$ \\
\hline NZP2014 & - & $\mathrm{Nod}^{+} \mathrm{Fix}^{+}$ & $112 \cdot 2$ & $\mathrm{Nod}^{+} \mathrm{Fix}^{+}$ & 167.9 \\
\hline NZP2037 & + & Nod $^{+} \mathrm{Fix}^{+}$ & $88 \cdot 6$ & $\mathrm{Nod}^{+} \mathrm{Fix}^{+}$ & $159 \cdot 1$ \\
\hline NZP2042 & - & Nod $^{+} \mathrm{Fix}^{+}$ & $105 \cdot 5$ & Nod ${ }^{+} \mathrm{Fix}^{+}$ & $150 \cdot 3$ \\
\hline NZP2085 & + & Nod $^{+} \mathrm{Fix}^{+}$ & $52 \cdot 1$ & Nod ${ }^{+} \mathrm{Fix}^{+}$ & $148 \cdot 2$ \\
\hline NZP2241 & + & $\mathrm{Nod}^{+} \mathrm{Fix}^{+}$ & $74 \cdot 7$ & $\operatorname{Nod}^{+} \mathrm{Fix}^{+}$ & $161 \cdot 4$ \\
\hline NZP2213 & + & $\mathrm{Nod}^{+} \mathrm{Fix}^{-}$ & $12 \cdot 9$ & Nod $^{+}$Fix $^{+}$ & $173 \cdot 4$ \\
\hline NZP2146 & + & Nod $^{+} \mathrm{Fix}^{-}$ & $13 \cdot 0$ & Nod $^{+} \mathrm{Fix}^{+}$ & $141 \cdot 3$ \\
\hline NZP2238 & + & $\mathrm{Nod}^{+} \mathrm{Fix}^{-}$ & $14 \cdot 1$ & $\mathrm{Nod}^{+} \mathrm{Fix}^{+}$ & $182 \cdot 5$ \\
\hline NZP2260 & + & Nod $^{+}$Fix $^{-}$ & $11 \cdot 8$ & Nod $^{+} \mathrm{Fix}^{+}$ & $160 \cdot 8$ \\
\hline Uninoculated & & & $13 \cdot 7$ & & $28 \cdot 4$ \\
\hline $\operatorname{LSD}(P=0.05)$ & & & $14 \cdot 1$ & & 13.5 \\
\hline
\end{tabular}

* Refer to Fig. 2.

there was little difference between the total dry weights of 6-week-old L. tenuis plants inoculated with each of these strains. On L. pedunculatus, five of the strains (NZP2014, NZP2037, NZP2042, NZP2085 and NZP2241) formed $\mathrm{Nod}^{+} \mathrm{Fix}^{+}$nodules while the remaining four formed ineffective $\left(\mathrm{Nod}^{+} \mathrm{Fix}^{-}\right)$nodules. There was considerable difference in the total dry weight of 6-week-old L. pedunculatus plants inoculated with each of the five $\mathrm{Nod}^{+} \mathrm{Fix}^{+}$strains (Table 4): the two plasmid-minus strains (NZP2014 and NZP2042) had produced significantly more plant growth than the three plasmid-containing strains (NZP2037, NZP2085 and NZP2241). Transfer of pRlo2037 into strains NZP2014 and NZP2042 gave derivatives (PN4206 and PN4225 respectively) that were significantly less effective on $L$. pedunculatus than either parent strain. This was particularly marked with strain PN4206 which formed $\mathrm{Nod}^{+} \mathrm{Fix}^{-}$ nodules on three out of six L. pedunculatus plants tested (data not shown).

\section{DISCUSSION}

The major result of this study was the observed increase in symbiotic effectiveness and competitiveness for $L$. pedunculatus shown by a plasmid-cured derivative of $R$. lot $i$ strain NZP2037. As reintroduction of the plasmid pRlo2037 (as plasmid pPN360) into the cured derivative (strain PN4010) resulted in a return to the NZP2037 level of symbiotic effectiveness and competitiveness for $L$. pedunculatus, the effects are clearly attributable to plasmid pRlo2037. This is the first report showing that an improvement in $\mathrm{N}_{2}$-fixing ability and competitiveness can be achieved by removing an indigenous plasmid from a Rhizobium strain.

The enhanced symbiotic effectiveness shown by strain PN4010 for $L$. pedunculatus and $L$. angustissimus appeared to be associated with an increased production of nodules rather than with an increase in nodule size or nodule nitrogenase activity. This increased production of nodules did not result from nodules appearing earlier on the roots of plants inoculated with strain PN4010 relative to PN4005 but rather from the ability of the strain to initiate more nodules. The effect is similar to the increase in nodule production and $\mathrm{N}_{2}$ fixation found for $R$. meliloti transconjugants harbouring the hairy root plasmid ( $\mathrm{pRi}$ ) of Agrobacterium rhizogenes (Strobel et al., 1985). DeJong et al. (1981) also reported differences in the number of nodules produced by transconjugants of a $R$. leguminosarum strain harbouring different $R$. leguminosarum sym plasmids, although in this case increased nodule number did not result in increased $\mathrm{N}_{2}$ fixation.

The lack of any significant improvement in effectiveness of strain PN4010 on L. tenuis may be related to the general capacity of $R$. loti strains to form $\mathrm{Nod}^{+} \mathrm{Fix}^{+}$nodules on this host. It is possible that the symbiotic potential of this symbiosis is already met by strain NZP2037. This is 
not the case with $L$. pedunculatus, a host upon which $R$. loti strains of the NZP2037-type are still significantly less effective than the best Bradyrhizobium sp. (Lotus) strains (Pankhurst \& Layzell, 1984; Wood et al., 1985).

Associated with the enhanced symbiotic effectiveness shown by strain PN4010 for $L$. pedunculatus was a significant improvement in its ability to compete against other $R$. lot $i$ and Bradyrhizobium sp. strains for nodulation of $L$. pedunculatus. This improvement was not associated with any discernible difference between strains PN4010 and PN4005 in their respective abilities to grow in the presence of a competing strain in the L. pedunculatus rhizosphere. A similar result was obtained by Brewin et al. (1983) in a study of sym plasmid effects on the competitiveness of $R$. leguminosarum. We thus conclude that the enhanced competitiveness shown by strain PN4010 relative to strains PN4005 and PN4012 is associated with the improved 'infectivity' or capacity to form nodules on $L$. pedunculatus.

Two of 34 wild-type strains of $R$. loti examined did not contain a plasmid. As with strain PN4010, the absence of a plasmid in the strains NZP2014 and NZP2042 correlated with superior effectiveness for $L$. pedunculatus. In addition, strain NZP2014 competed equally with strain PN4010 in the competition study, suggesting that this strain may also be superior to other wild-type $R$. loti strains in competing for nodulation of $L$. pedunculatus. Transfer of pRlo2037 into the two wild-type strains NZP2014 and NZP2042 gave derivatives that were less effective in $\mathrm{N}_{2}$ fixation on $L$. pedunculatus than either parent strain. This effect, which paralleled the reduction in effectiveness for $L$. pedunculatus found for PN4012 following re-introduction of pRlo2037, showed that pRlo2037 can suppress the nodulating capacity of strains other than NZP2037. As pRlo2037 does not carry genes directly involved in nodulation or $\mathrm{N}_{2}$ fixation per se (Chua et al., 1985) it will be of interest to elucidate the nature of the determinants that are responsible for this suppression, and to see if plasmids similar to pRlo2037 exist in other rhizobia. As most Rhizobium strains which contain a sym plasmid also contain other plasmids (Dénarié et al., 1981), it is possible that interactions between the plasmids may be equally significant in determining the success of the symbiosis.

We wish to thank Margaret Soulsby for providing the photograph and Professor Barry Scott for valuable discussions throughout this work.

\section{REFERENCES}

Banfalvi, Z., Sakanyan, V., Koncz, C., Kiss, A., Dusha, I. \& Kondorosi, A. (1981). Location of nodulation and nitrogen fixation genes on a high molecular weight plasmid of $R$. meliloti. Molecular and General Genetics 184, 318-325.

Brewin, N. J., WoOd, E. A. \& Young, J. P. W. (1983). Contribution of the symbiotic plasmid to the competitiveness of Rhizobium leguminosarum. Journal of General Microbiology 129, 2973-2977.

Chua, K.-Y., Pankhurst, C. E., MacDonald, P. E., HOPCROFT, D. H., JAR VIS, B. D. W. \& SCOTT, D. B. (1985). Isolation and characterization of transposon Tn5-induced symbiotic mutants of Rhizobium loti. Journal of Bacteriology 162, 335-343.

DeJong, T. M., Brewin, N. J. \& Phillips, D. A. (1981). Effects of plasmid content in Rhizobium leguminosarum on pea nodule activity and plant growth. Journal of General Microbiology 124, 1-7.

Dénarié, J., Boistard, P., Casse-Delbart, F., Atherly, A. G., Berry, J. O. \& Russell, P. (1981). Indigenous plasmids of Rhizobium. In International Review of Cytology Supplement 13, pp. 225-246. Edited by K. L. Giles \& A. G. Atherly. New York: Academic Press.

ECKHARDT, T. (1978). A rapid method for the identification of plasmid deoxyribonucleic acid in bacteria. Plasmid 1, 584-588.
Haugland, R. \& Verma, D. P. S. (1981). Interspecific plasmid and genomic DNA sequence homologies and localization of nif genes in effective and ineffective strains of Rhizobium japonicum. Journal of Molecular and Applied Genetics 1, 205-217.

Jarvis, B. D. W., Pankhurst, C. E. \& Patel, J. J. (1982). Rhizobium loti, a new species of legume root nodule bacteria. International Journal of Systematic Bacteriology 32, 378-380.

JORDAN, D. C. (1984). Genus I. Rhizobium Frank 1889, 338. In Bergey's Manual of Systematic Bacteriology, vol. 1, pp. 235-242. Edited by N. R. Krieg \& J. G. Holt. Baltimore \& London: Williams \& Wilkins.

Kondorosi, A., Kiss, G. B. \& Dusha, I. (1984). Plasmids governing symbiotic nitrogen fixation. In Current Developments in Biological Nitrogen Fixation, pp. 135-171. Edited by N. S. Subba Rao. New Delhi: Oxford \& IBH Publishing Co.

Masterson, R. V., Russell, P. R. \& Atherly, A. G. (1982). Nitrogen fixation (nif) genes and large plasmids of Rhizobium japonicum. Journal of Bacteriology 152, 928-931.

Miller, J. M. (editor) (1972). Experiments in Molecular Genetics. Cold Spring Harbor, NY: Cold Spring Harbor Laboratory.

PankHURST, C. E. (1977). Symbiotic effectiveness of antibiotic-resistant mutants of fast- and slow-grow- 
ing strains of Rhizobium nodulating Lotus species. Canadian Journal of Microbiology 23, 1026-1033.

Pankhurst, C. E. (1981). Effect of plant nutrient supply on nodule effectiveness and Rhizobium strain competition for nodulation of Lotus pedunculatus. Plant and Soil 60, 325-339.

PANKhuRST, C. E. (1986). Genetics and molecular biology of symbiotic nitrogen fixation by Rhizobium sp. and $R$. japonicum. In Nitrogen Fixation $I V$. Molecular Biology. Edited by W. J. Broughton \& A. Pühler. Oxford: Oxford University Press (in the Press).

Pankhurst, C. E. \& Jones, W. T. (1979). Effectiveness of Lotus root nodules. II. Relationship between root nodule effectiveness and 'in vitro' sensitivity of fast-growing Lotus rhizobia to flavolans. Journal of Experimental Botany 30, 1095-1107.

Pankhurst, C. E. \& LAyzell, D. B. (1984). The effect of bacterial strain and temperature changes on the nitrogenase activity of Lotus pedunculatus root nodules. Physiologia plantarum 62, 404-409.

Pankhurst, C. E., Broughton, W. J. \& Wieneke, U. (1983). Transfer of an indigenous plasmid of Rhizobium loti to other rhizobia and Agrobacterium tumefaciens. Journal of General Microbiology 129, 2535-2543.

ScoTT, D. B. \& Ronson, C. W. (1982). Identification and mobilization by cointegrate formation of a nodulation plasmid in Rhizobium trifolii. Journal of Bacteriology 151, 36-43.

Strobel, G. A., Lam, B., Harrison, L., Hess, B. M. \& LAM, S. (1985). Introduction of the hairy root plasmid in Rhizobium meliloti results in increased nodulation on its host. Journal of General Microbiology 131, 355-361.

WOOD, S. M., Layzell, D. B., NeWCOMB, W. \& PANkhurst, C. E. (1985). A morphometric study of effective nodules induced by Rhizobium loti and Bradyrhizobium sp. (Lotus) on Lotus pedunculatus. Canadian Journal of Botany 63, 43-53. 